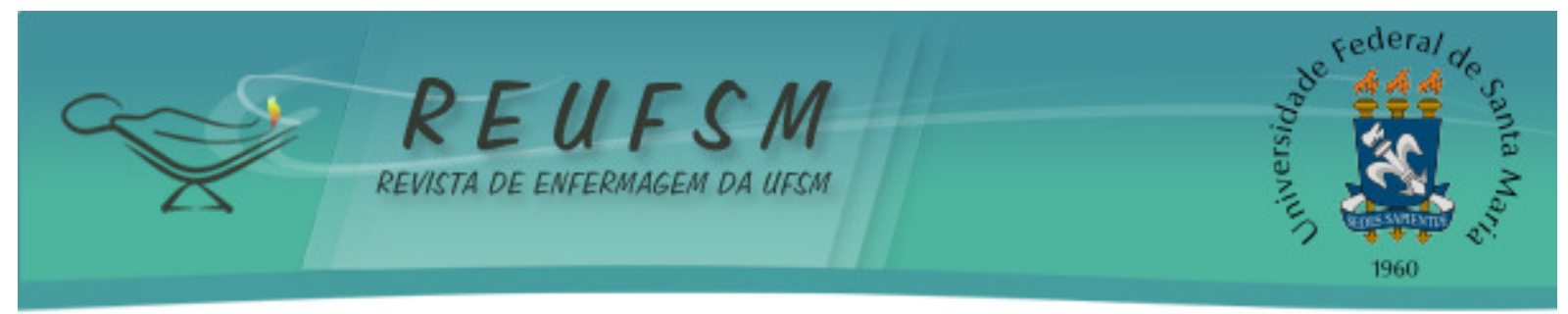

\title{
EDUCAÇÃO PERMANENTE EM SAÚDE: CONCEPÇÕES E PRÁTICAS DOS ENFERMEIROS NA ESTRATÉGIA SAÚDE DA FAMÍLIA
}

\author{
PERMANENT HEALTH EDUCATION: NURSES' CONCEPTIONS AND PRACTICES \\ IN THE FAMILY HEALTH STRATEGY
}

\section{EDUCACIÓN PERMANENTE EN SALUD: CONCEPCIONES Y PRÁCTICAS DE LOS ENFERMEROS EN LA ESTRATEGIA SALUD DE LA FAMILIA}

\author{
Greici Kelli Tolotti ${ }^{1}$ \\ Adriana Rotoli ${ }^{2}$ \\ Marinês Aires ${ }^{3}$
}

Doi: $10.5902 / 2179769225273$

RESUMO: Objetivo: conhecer as concepções e práticas de Educação Permanente em Saúde dos enfermeiros nas Estratégias de Saúde da Família de um município da Região Noroeste do Estado do Rio Grande do Sul, bem como identificar os fatores que favorecem e os que dificultam estas práticas. Método: pesquisa qualitativa, descritiva e exploratória, realizada no segundo semestre de 2015. Os dados foram coletados por meio de entrevistas semiestruturadas com quatro enfermeiros e analisadas pela Análise Temática. Resultados: emergiram três categorias: Concepções dos enfermeiros de Estratégia de Saúde da Família sobre Educação Permanente em Saúde; Práticas de Educação Permanente em Saúde realizadas pelos enfermeiros na Estratégia de Saúde da Família: articulando a equipe multiprofissional; Fatores que favorecem e que dificultam a realização de Educação Permanente em Saúde na Estratégia de Saúde da Família. Considerações Finais: a análise mostrou que há uma concepção arraigada de conceitos de Educação Continuada e Educação em Saúde ao de Educação Permanente em Saúde. Há necessidade de maiores discussões acerca da Educação Permanente em Saúde no município, com vistas à implementação desta política, qualificando as equipes e os seus processos de trabalho.

Descritores: Educação Continuada; Estratégia Saúde da Família; Enfermagem.

ABSTRACT: Aim: to know the Permanent Health Education concepts and practices of the Family Health Strategies nurses of a municipality in the North Western Region of Rio Grande do Sul and identify the factors that favor and hinder these practices. Method: qualitative, descriptive and exploratory research conducted in the second semester of 2015. Data were collected through semi-structured interviews with four nurses and analyzed by the Thematic Analysis. Results: three categories emerged: Family Health Strategies nurses' conceptions about Permanent Health Education; Permanent Health Education practices performed by the nurses in the Family Health Strategies: articulating the multiprofessional team; Factors that favor and hinder the performance of Permanent Health Education in the Family Health Strategies. Final

\footnotetext{
${ }^{1}$ Enfermeira. Universidade Regional Integrada do Alto Uruguai e das Missões - URI Campus Frederico Westphalen. Frederico Westphalen. Rio Grande do Sul. Brasil. E-mail: greici.kellitolotti@gmail.com

${ }^{2}$ Enfermeira. Mestre em Enfermagem. Professora do Curso de Graduação em Enfermagem, Universidade Regional Integrada do Alto Uruguai e das Missões - URI Campus Frederico Westphalen. Frederico Westphalen. Rio Grande do Sul. Brasil. E-mail: rotoli@uri.edu.br

${ }^{3}$ Enfermeira. Doutora em Enfermagem. Professora do Curso de Graduação em Enfermagem, Universidade Regional Integrada do Alto Uruguai e das Missões - URI Campus Frederico Westphalen. Frederico Westphalen. Rio Grande do Sul. Brasil. E-mail: maires@uri.edu.br
} 


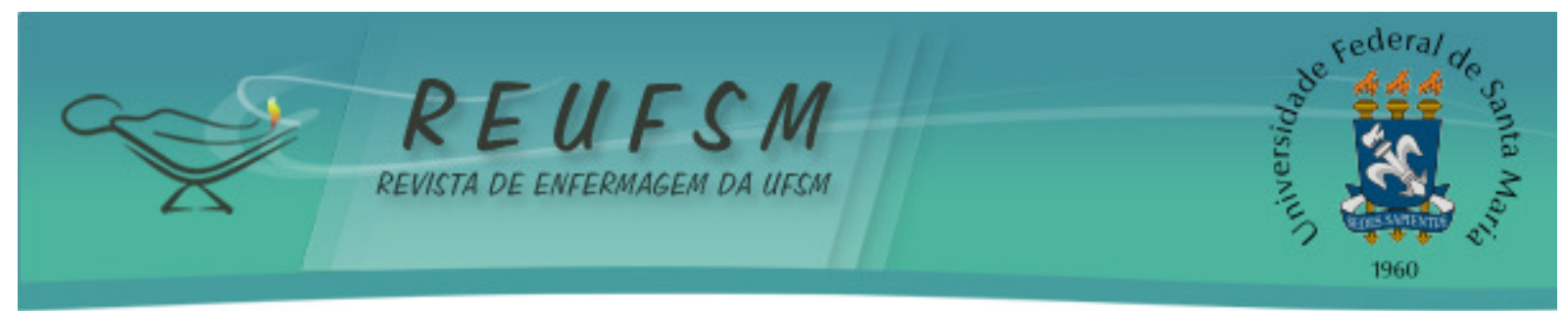

Considerations: the analysis showed that there is a deep-rooted connection among the concepts of Continuing Education and Health Education to that of Permanent Health Education. There is need for further discussions about the Permanent Health Education in the city, with a view of implementing this policy, qualifying the teams and their work processes.

Descriptors: Education, Continuing; Family Health Strategy; Nursing.

RESUMEN: Objetivo: conocer las concepciones y prácticas de la Educación Permanente en Salud de los enfermeros de la Estrategia de Salud de la Familia, de una ciudad de la Región Noroeste del Estado de Rio Grande do Sul, e identificar los factores que contribuyen y los que dificultan estas prácticas. Método: investigación cualitativa, descriptiva y exploratoria desarrollada en la segunda mitad de 2015. Los datos fueron recolectados por medio de entrevistas semiestructuradas con cuatro enfermeros y analizados con base en Análisis Temática. Resultados: surgieron tres categorías: las concepciones de los enfermeros de la Estrategia de Salud de la Familia sobre Educación Permanente en Salud; las prácticas de Educación Permanente en Salud realizadas por los enfermeros en la Estrategia de Salud de la Familia: articulando el equipo multiprofesional; factores que contribuyen y dificultan la realización de Educación Permanente en Salud, en la Estrategia de Salud de la Familia. Consideraciones Finales: el análisis evidenció que hay concepciones arraigadas sobre conceptos de Educación Continuada y Educación en Salud al de Educación Permanente en Salud. Hay necesidad de más discusiones sobre la Educación Permanente en Salud en la ciudad, con el objetivo de implementar esta política, calificando los equipos y sus procesos de trabajo.

Descriptores: Educación Continua; Estrategia de Salud Familiar; Enfermería.

\section{INTRODUÇÃO}

No contexto do processo da Reforma Sanitária Brasileira e das mudanças ocorridas no modelo de atenção à saúde, a partir da década de 1980, com a criação do Sistema Único de Saúde (SUS) houve também a necessidade formular políticas de educação e desenvolvimento dos trabalhadores para atuarem nesse sistema.

Essa necessidade adveio, principalmente, da adoção de um modelo de atenção orientado pela Atenção Primária à Saúde (APS), o qual se deu através da grande expansão de unidades de APS em diversos municípios do país e, posteriormente, pela criação do Programa de Saúde da Família (PSF) no ano de 1994. Foi reformulado para Estratégia de Saúde da Família (ESF) em 1997, que teve o intuito de agregar qualidade ao processo de expansão. ${ }^{1}$

A ESF viabilizou um novo e amplo campo de atuação para os profissionais da saúde, pois buscou descontruir o tradicional modelo médico-curativista, e adotar um modelo centrado no indivíduo, e não na doença, com foco na família e na comunidade, organizado por equipes multiprofissionais e interdisciplinares inseridas no contexto em que as pessoas vivem. ${ }^{2}$ 


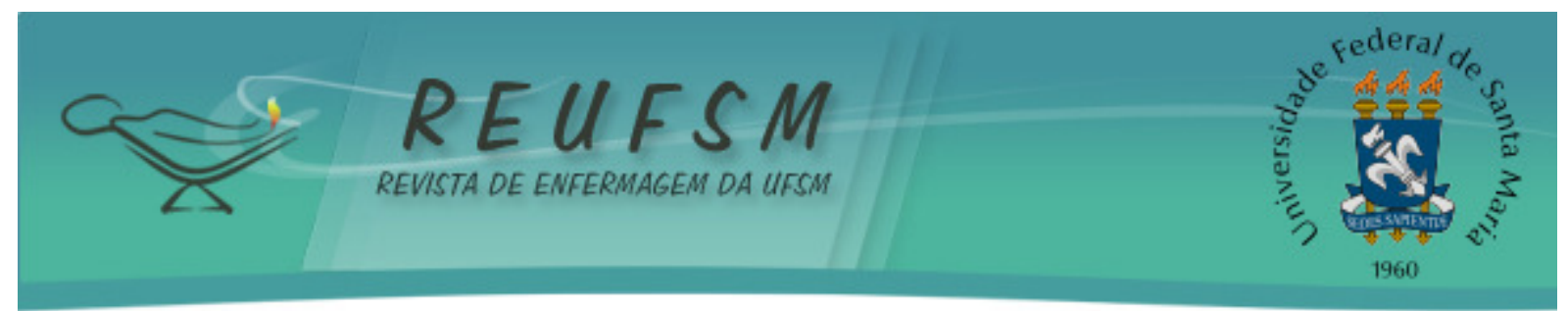

Com estas mudanças buscaram-se alternativas às metodologias tradicionais de ensino-aprendizagem, uma vez que, evidenciaram-se novas demandas aos serviços de saúde, o que colocou em debate o uso de diferentes abordagens metodológicas da educação de trabalhadores para a saúde. Dentre essas, encontra-se a Educação Continuada, metodologia de ensino-aprendizagem, centralizada na atualização de conhecimentos que, de maneira geral, trata de conteúdos específicos previamente elaborados, verticalizados, descontínuos e que, em muitas vezes, não conseguem abarcar o contexto político institucional dos serviços de saúde e a realidade da comunidade que atendem. ${ }^{3}$

E como alternativa significativa a anteriormente citada, a Educação Permanente em Saúde (EPS), a qual foi instituída política pública pela Portaria GM/MS n ${ }^{\circ} 1.996$, de 20 de agosto de 2007 e para tanto, configura-se como eixo organizador da política de trabalho para o SUS. A EPS se orienta por uma lógica de Educação na Saúde e de ensino-aprendizagem que se incorpora de forma global e contínua ao cotidiano dos serviços de saúde, pautada na prática problematizadora das situações cotidianas como fonte de conhecimento e de busca de alternativas para a cogestão dos problemas encontrados, favorecendo o olhar crítico e a explicação da realidade vivida pelos atores envolvidos. ${ }^{3,4}$

Com base nesses aspectos, a Política Nacional de Atenção Básica (PNAB) instituída em 2006, e posteriormente reformulada em 2011, prevê a atuação do enfermeiro generalista ou especialista em saúde da família como membro da equipe mínima e ampliada da ESF. A mesma trata das atribuições desse profissional e prevê que deve "contribuir, participar e realizar atividades de EPS da equipe de enfermagem e outros membros da equipe."

Ao assumir novos papéis frente às crescentes mudanças no modelo de atenção e a complexidade do cenário do trabalho em saúde, o enfermeiro vem ampliando o seu campo de atuação e necessita da mobilização de novos conhecimentos e competências. ${ }^{2}$ Pressupõese que o enfermeiro deva conhecer e contribuir com o desenvolvimento de ações de EPS na ESF, atuando como facilitador na viabilização de práticas cotidianas problematizadoras da realidade vivida.

A pertinência deste estudo justifica-se pelas lacunas encontradas na literatura sobre o tema, uma vez que tem demonstrado um frequente distanciamento dos profissionais de saúde 


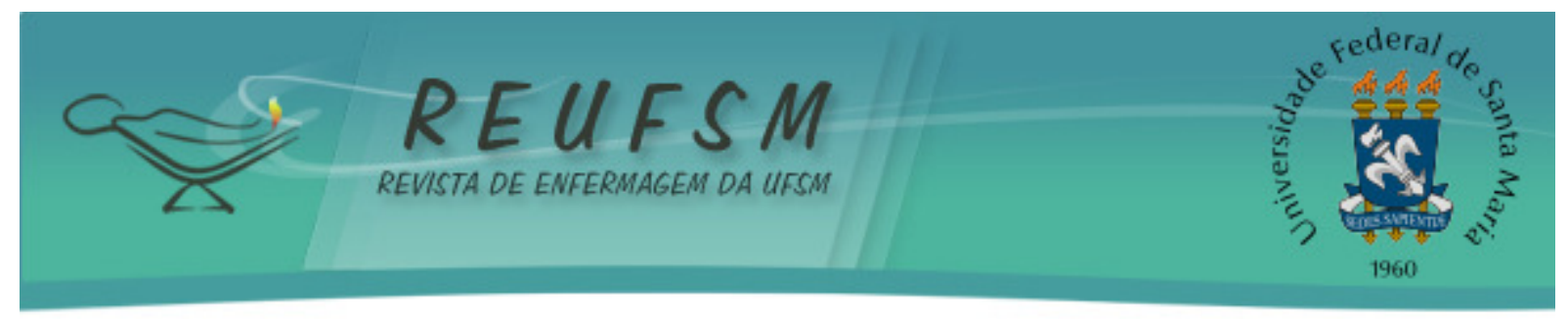

em relação ao conceito da EPS, o que tem se traduzido em dificuldades na aplicação deste dispositivo no cotidiano de atuação dos profissionais. ${ }^{4}$

Face ao exposto, este estudo teve a seguinte questão de pesquisa: Quais são as concepções e práticas de Educação Permanente em Saúde dos enfermeiros nas Estratégias de Saúde da Família de um município da Região Noroeste do Estado do Rio Grande do Sul e quais são os fatores que favorecem e os que dificultam estas práticas? Para entender esta problemática, os objetivos deste estudo foram: conhecer as concepções e práticas de EPS dos enfermeiros das ESF de um município da Região Noroeste do Estado do Rio Grande do Sul, e identificar os fatores que favorecem e os que dificultam estas práticas.

\section{MÉTODO}

Pesquisa descritiva exploratória com abordagem qualitativa, desenvolvida em um município da Região Noroeste do Estado do Rio Grande do Sul, no segundo semestre de 2015. O referido município conta com seis Unidades de Saúde da Família com, pelo menos, a equipe mínima. Utilizou-se como critério de inclusão atuar na equipe de ESF.

Participaram do estudo quatro enfermeiros, de um total de seis enfermeiros das ESF. Os profissionais que não participaram da pesquisa foram uma enfermeira que estava em afastamento do trabalho por atestado médico no período de coleta de dados e a outra não respondeu as solicitações de participação do mesmo.

A coleta dos dados foi realizada por meio de entrevista semiestruturada nas Unidades de Saúde da Família e agendada previamente conforme a disponibilidade dos participantes. As entrevistas foram gravadas em dispositivo de áudio e posteriormente transcritas na íntegra. Utilizou-se um roteiro baseado na questão de pesquisa, nos seus objetivos e em um estudo realizado por Miccas FL e Batista SHSS (2014) ${ }^{4}$ que teve como o objetivo realizar Metassíntese da literatura sobre os principais conceitos e práticas relacionados à educação permanente em saúde.

A Metassíntese serviu de base para a realização do estudo por tratar-se de uma modalidade de revisão de literatura que compila, sintetiza e traduz estudos sobre determinado tema, neste caso a EPS, apresentando uma ampla compreensão e, assim auxiliou na exploração do tema neste estudo. 


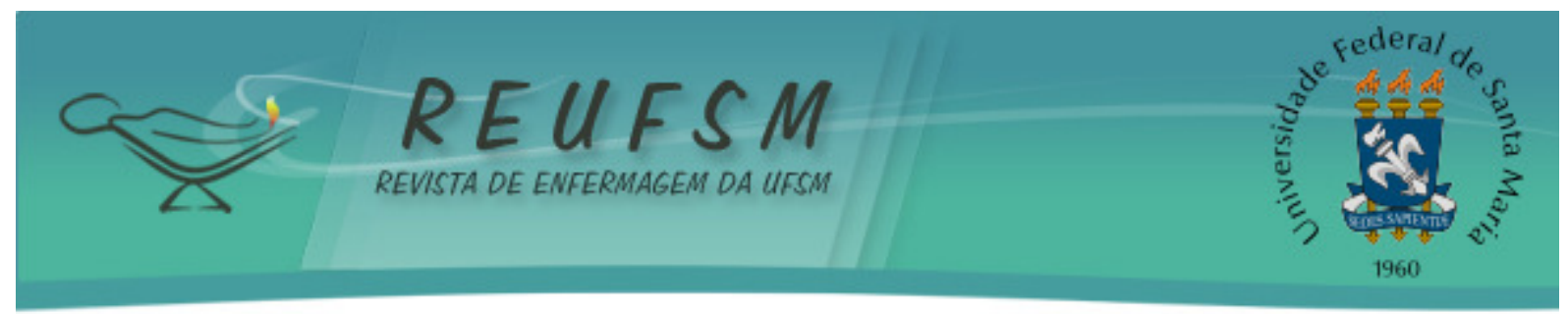

Para análise das informações, utilizou-se a análise temática que compreendeu três etapas: pré-análise, exploração do material e tratamento dos resultados obtidos e interpretação. ${ }^{6}$

A pesquisa seguiu todas as etapas previstas pela Resolução 466/12 sobre pesquisas que envolvem seres humanos, conforme Código de Ética do Conselho Nacional de Saúde do Ministério da Saúde. ${ }^{7}$ Para garantir a confidencialidade dos participantes desta pesquisa, os seus nomes foram codificados pela letra "E" (Enfermeiro) e um número de sequência dos participantes. Também esta pesquisa foi Aprovada pelo Comitê de Ética em Pesquisa pelo Parecer de $\mathrm{N}^{\mathrm{o}}$ 1.144.746 emitido no dia 17/07/2015.

\section{RESULTADOS E DISCUSSÕES}

Considerando os objetivos propostos, após análise das entrevistas elaborou-se três categorias principais, quais sejam: concepções dos enfermeiros de Estratégia de Saúde da Família sobre Educação Permanente em Saúde; Práticas de Educação Permanente em Saúde realizadas pelos enfermeiros na Estratégia de Saúde da Família: articulando a equipe multiprofissional; e, Fatores que favorecem e que dificultam a realização de Educação Permanente em Saúde na Estratégia de Saúde da Família.

\section{Concepções dos enfermeiros de Estratégia de Saúde da Família sobre Educação}

\section{Permanente em Saúde}

Acerca da concepção de EPS, alguns participantes relacionaram-na com atualização de conhecimentos e aprimoramento necessário, frente às crescentes mudanças que ocorrem no âmbito da ESF.

Eu entendo por EPS todo e qualquer aprimoramento, atualização $e$ estudo realizado durante o horário de trabalho ou não, ou busca com especializações, cursos, outras atividades, ou até leituras. (E4)

O que eu entendo é que é uma ferramenta muito importante e essencial, porque a todo o momento ocorrem mudanças. (E2)

Conforme as falas acima, por vezes à concepção de EPS é compatível com os reais objetivos da mesma quando os participantes se referem ao estudo realizado no trabalho e a necessidade de EPS, pelas mudanças que ocorrem. Porém, há um conflito de entendimento conceitual entre EPS e Educação Continuada, pois associam a EPS a cursos e especializações, mais adequados ao conceito de Educação Continuada. Outros estudos ${ }^{4,8,12}$ já demonstraram 


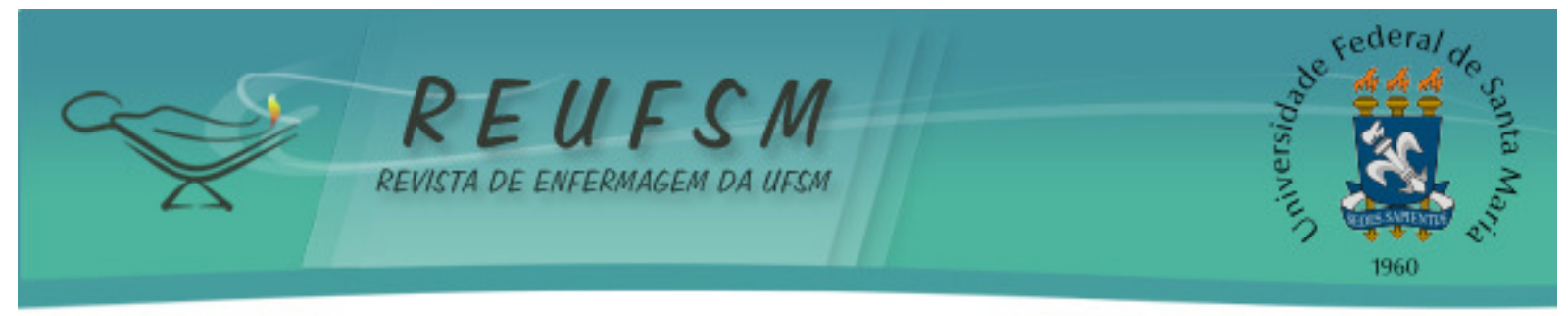

este conflito entre os dois conceitos. Vale ressaltar que a atualização dos conhecimentos deve ter cunho horizontal, ou seja, atualização embasada nas situações cotidianas, permeadas por discussões na equipe, com o objetivo de transformar as práticas de saúde e a realidade vivida.

A EPS também foi relacionada, diretamente, com o conceito de Educação em Saúde, fazendo menção ao vínculo do profissional com a comunidade com o intuito de promover saúde e autocuidado, sem referir-se a EPS como educação voltada para a problematização do vivido no cotidiano do trabalho na equipe de saúde da família.

A Educação Permanente é o vínculo que o profissional tem com a comunidade, levando informações, a troca de conhecimentos. E o permanente, no caso, é manter esse vínculo, que isso venha ocorrendo mais vezes. (E3)

A fala acima demonstra um conflito entre o conceito de EPS, que pode ser caracterizada como Educação na Saúde que é voltada para a qualificação dos profissionais e do processo de trabalho enquanto equipe e, a Educação em Saúde, a qual é voltada para ações desenvolvidas com os indivíduos e a comunidade. ${ }^{9}$ Resultados semelhantes também foram encontrados em um estudo com Enfermeiros que atuam na atenção básica em 26 municípios pertencentes a $19^{\mathrm{a}}$ Coordenadoria Regional da Saude. ${ }^{12}$ Para os autores, a articulação entre educação e saúde e EPS mencionado pelos Enfermeiros é um desafio que envolve interfaces de diversos saberes e, por outro lado, é uma articulação imprescindível para que possam ser realizadas ações efetivas de EPS que requerem a articulação entre ensino, serviço, gestão e controle social.

Ações de Educação em Saúde são importantes e intrínsecas às equipes de ESF, porém é necessária a compreensão do processo de trabalho e de como se dá o diálogo da equipe para o planejamento e organização destas ações. Também de que modo as equipes priorizam e realizam discussões acerca das necessidades de ações a serem desenvolvidas com a comunidade, se elas se orientam através da EPS e se utilizam de suas estratégias para o aperfeiçoamento e qualificação deste processo.

\section{Práticas de Educação Permanente em Saúde realizadas pelos enfermeiros na Estratégia de Saúde da Família: articulando a equipe multiprofissional}

Em relação às práticas de EPS e sua realização junto à equipe, os participantes ressaltam a discussão de casos e o enfoque prioritário das reuniões de equipe na atualização sobre temas específicos como, por exemplo, as campanhas ministeriais e o 


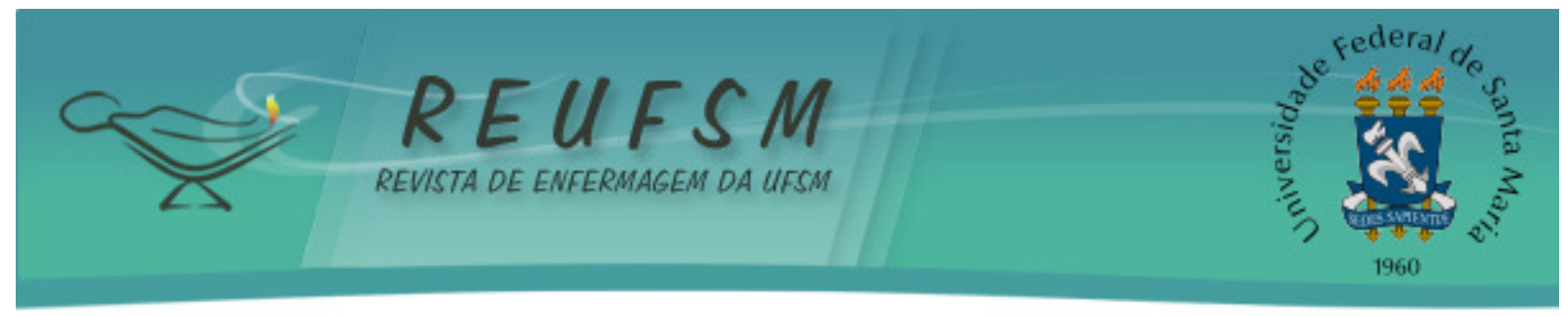

calendário vacinal. No entanto, é sabido que estes temas são verticalizados de modo que, nem sempre, reproduzem o cotidiano da realidade das equipes.

A principal delas é durante a sexta-feira que a gente faz a reunião de equipe, na qual casos pré-definidos são discutidos. (E1)

Nós temos todas as terças-feiras reunião de equipe. Como agora nós temos a campanha do HPV, reunimos toda a equipe, ressaltamos a importância de qual é a idade, que como é uma norma, nova no calendário vacinal. (E3)

A discussão de casos nas reuniões de equipe evidenciada por um dos participantes tem importante papel no planejamento e articulação das ações de diversos profissionais da equipe de Saúde da Família, frente a um caso específico.

Dessa forma, fomenta o cuidado interdisciplinar e amplia a capacidade de resolutividade na APS, buscando superar a fragmentação do cuidado, haja vista a complexidade, cada vez maior, dos casos que se apresentam como demandas na APS. ${ }^{1}$

Ainda, no que se refere à discussão de casos há, de fato, um avanço para a superação da fragmentação do cuidado e a qualificação da atenção à saúde dos usuários, como é demonstrado no trecho citado a seguir:

[...] desaparece o predomínio do núcleo especializado da profissão ou da especialidade; emergem colateralidades, buscando vigência na definição do conhecimento útil e oportuno, que pode se expressar no trabalho, na sua organização e na qualidade das respostas que o trabalhador e a equipe oferecem, buscando qualificar a atenção à saúde em função das necessidades singulares dos usuários. ${ }^{10: 149}$

Mediante as falas, percebe-se a associação de EPS com temas pontuais, como é o caso das campanhas e modificações em programas ministeriais, sendo mais discutidos e trabalhados na equipe. Resultado semelhante foi encontrado em estudo ${ }^{11}$ no que temas pontuais são citados como parte do rol de atividades que a EPS abrange, mas que não esgotam a gama de questões e podem ser trabalhadas e discutidas na ESF, que envolve todo o processo de trabalho no SUS na sua amplitude e complexidade, sugerindo fluxos de problematização de temas como redes de atenção à saúde, clínica ampliada, humanização e linhas de cuidado, protocolos assistenciais, dentre outras tantas possibilidades.

Cabe ressaltar que um participante evidencia práticas pertinentes à EPS como a busca por estudos, conhecimento das delimitações das atribuições dos profissionais, para que 


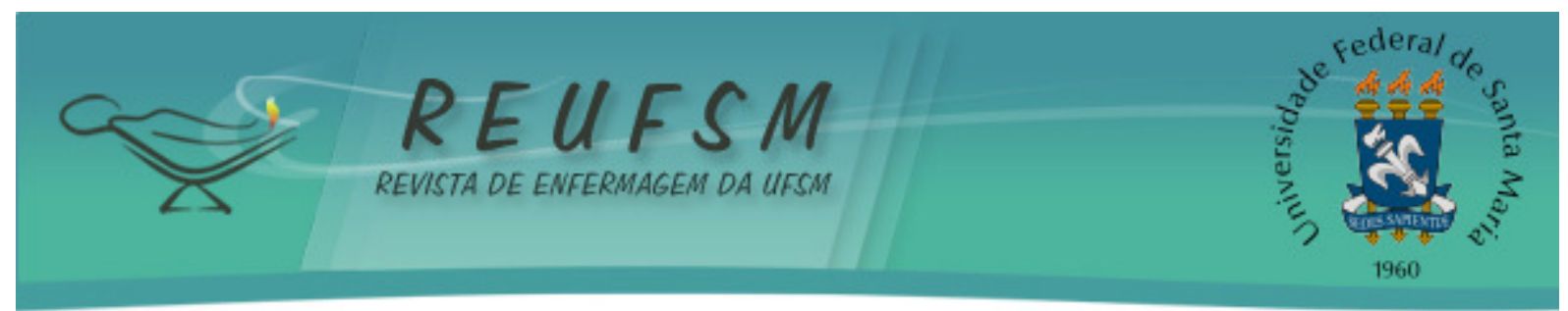

então as situações possam ser problematizadas junto à equipe, levando em consideração a realidade local, balizando suas ações nos princípios da ESF.

Para começar, leituras e estudos meus com relação ao que é a ESF, as atividades, atribuições de cada um com relação ao que pode ser feito e ao que não pode ser feito, o que pode ser implantado, implementado e aprimorado, mediante o que temos de realidade no município. (E4)

Estas práticas evidenciadas acima demonstram um fator importante para $\mathrm{o}$ entendimento da dimensão que a EPS deve ter no cotidiano do serviço em que o profissional atua. Isso porque, a busca por novas leituras, estudos, deve ser baseada, primariamente, na qualificação do processo de trabalho, das práticas coletivas, de modo que fica evidente o comprometimento quanto à qualificação do objeto de trabalho da ESF e a qualificação específica do profissional no campo técnico individual, tornando-se complementar neste processo e indo ao encontro dessa política.

\section{Fatores que favorecem e que dificultam a realização de Educação Permanente em Saúde na Estratégia de Saúde da Família}

O levantamento das necessidades de saúde no cotidiano do território da ESF por meio dos ACS, foi um importante fator facilitador referenciado pelos participantes.

Elas (ACSs) me trazem um caso em tese. Elas são os nossos olhos perante a comunidade. (E1)

Busco priorizar o que elas (ACSs) encontram no cotidiano, o que é a maior demanda delas. (E2)

Por meio das falas acima, os enfermeiros relatam considerar e priorizar as demandas levadas pelos ACS. No entanto, não há menção sobre como o enfermeiro e os demais profissionais da equipe atuam para promover estratégias de EPS que problematizem os casos e auxiliem na atuação dos ACS junto às equipes e às comunidades que eles assistem.

Nesse sentido, um estudo semelhante destaca que "o enfermeiro assumiu para si a responsabilidade pela qualificação dos ACS, estabelecendo uma relação de transmissão de saberes para esses profissionais e não uma relação de troca."12:609 Assim, é imprescindível a inclusão do ACS nas atividades da unidade de saúde e no planejamento conjunto das visitas 


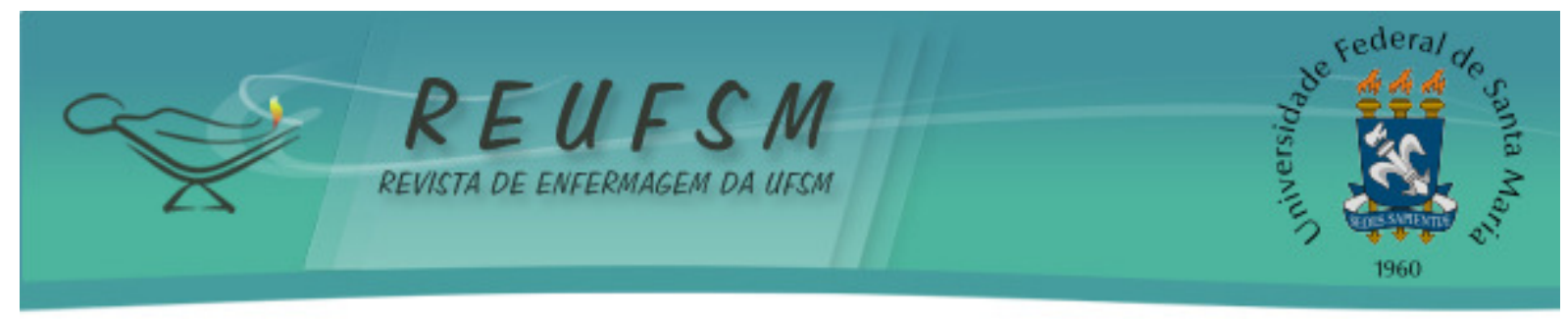

domiciliares, visando à abrangência, cada vez maior, da realidade local do território da ESF nas discussões da equipe de saúde da família.

Um dos fatores relatados pelos participantes que favorece as práticas de EPS é o interesse da equipe e a sua motivação para o trabalho na ESF. Estes fatores também foram associados às dificuldades quando não estão presentes.

$O$ interesse da equipe. Então, o que favorece é a motivação, é a vontade da equipe de que aquilo dê certo. $O$ que dificulta é essa falta de motivação da equipe. (E4)

Devido à complexidade do trabalho no SUS, em especial na ESF pela sua abrangência e inserção política e social no cenário da municipalização da atenção a saúde, há demandas constantes de aperfeiçoamento e qualificação dos trabalhadores, tendo o enfermeiro o papel central de articulação destas equipes na organização dos processos de trabalho. Este necessita, ainda mais, de qualificação e motivação para que atue de modo responsável, pautado na integralidade de suas ações, sendo um mediador do trabalho em equipe.

Estudo sobre revisão sistemática ${ }^{4}$ demonstrou fatores que influenciam negativamente na motivação e na viabilização de estratégias de EPS, no cotidiano de trabalho destes profissionais como, a alta rotatividade de profissionais, predomínio da formação centrada na atuação hospitalar e na imprecisão no entendimento de conceitos como integralidade e promoção da saúde.

A falta de capacitações e cursos fora do ambiente de trabalho foi evidenciada como uma deficiência das ESF do município.

Mas o que eu sinto bastante falta é de capacitações fora do ambiente de trabalho, não só nós aqui da equipe, nós das ESF, mas fora, extra. (E2)

A preocupação dos profissionais com a oferta de capacitações fora do ambiente da ESF define uma linha de pensamento voltada para a Educação Continuada, verticalizada e específica, fato este que, provavelmente, sustenta-se na compreensão insuficiente da EPS como uma gama de ferramentas diferenciadas que têm o potencial, muitas vezes, de suprir esta demanda sentida pelos profissionais que atuam em um cenário tão sujeito às mudanças.

É evidente que há necessidade dos diversos núcleos profissionais de se aprofundarem em determinadas questões mais específicas e especializadas das suas áreas de atuação. Porém, esta necessidade deve estar integrada às necessidades globais 


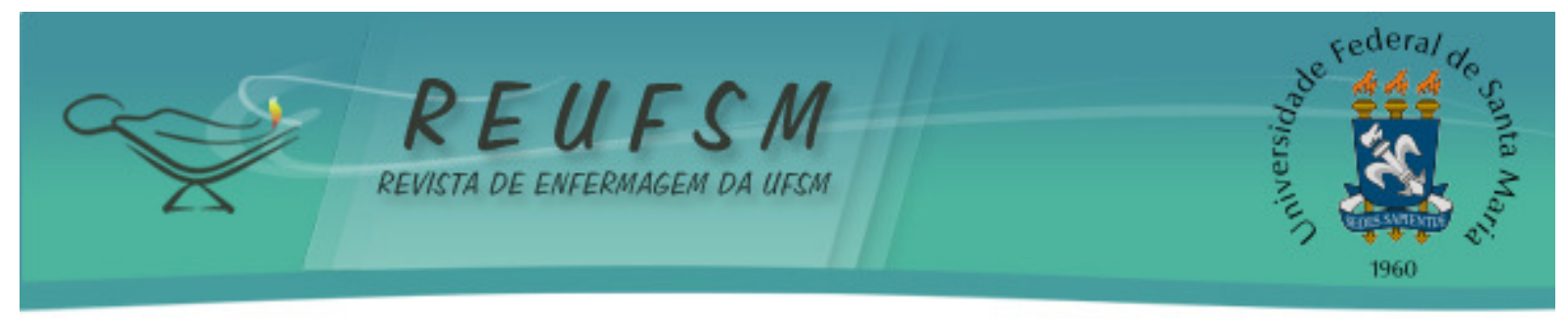

de qualificação do processo de trabalho da ESF, assim favorecendo a viabilização de práticas de EPS. $^{13}$

Pode-se considerar que a EPS e a Educação Continuada tem um caráter complementar, não excludente. ${ }^{14}$ No entanto, ainda vê-se uma prevalência de concepções que confundem EPS com Educação Continuada ou com Educação em Saúde, além da busca por capacitações nos moldes disciplinares, que podem ser substituídas por estratégias de EPS e, assim, promoverem maior impacto na realidade local das equipes.

\section{CONSIDERAÇÕES FINAIS}

A pesquisa demonstrou há algumas concepções arraigadas ao modelo tradicional de educação. Ainda que isoladamente, alguns enfermeiros demonstram o uso de ferramentas de EPS para as discussões nas reuniões de equipe, para a atualização técnica. No entanto, estas necessitam de maior adequação ao cotidiano das equipes e maior articulação com o Modelo de Atenção da APS e das ESF.

Ressalta-se a sobreposição dos conceitos de Educação Continuada e Educação em Saúde ao de EPS, demonstrando lacunas no conhecimento das políticas de saúde vigentes no SUS e de proposições para a efetivação de seus princípios e viabilização dos avanços necessários na sua contínua qualificação.

As limitações desta pesquisa estão na impossibilidade de generalização dos resultados, pois estes decorreram da abordagem qualitativa, estando limitados em um tempo e contexto específicos. Assim, sugere-se a ampliação em novas pesquisas, a partir de outros grupos amostrais e outras perspectivas metodológicas, para que sejam aprofundadas as reflexões sobre a EPS.

A pesquisa contribuiu para uma reflexão dos enfermeiros das ESF sobre a EPS e sobre o próprio cotidiano de trabalho em que estão inseridos. Espera-se que ainda venha a contribuir para formulação de estratégias, juntamente com a gestão municipal, possibilitando a realização de maiores discussões sobre esta política e sua efetiva implementação no município. 


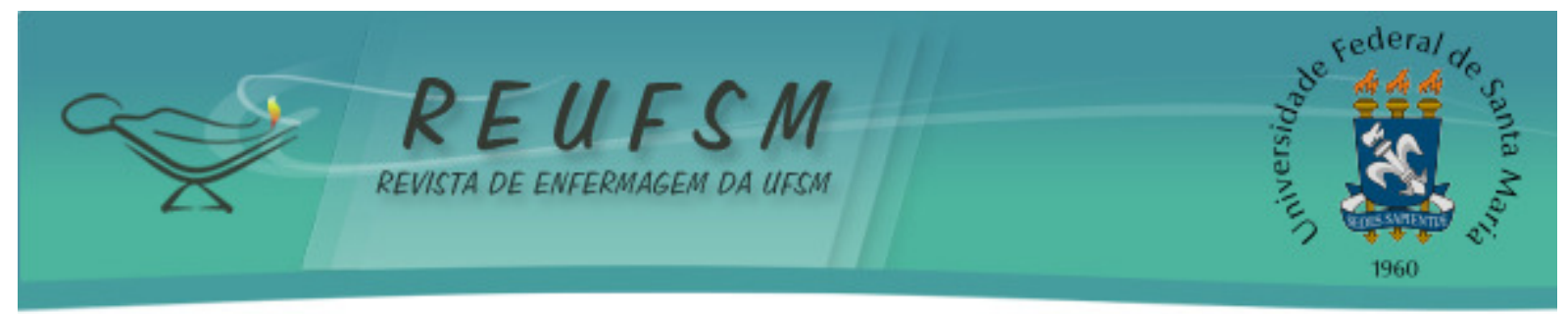

\section{REFERÊNCIAS}

1. Mendes EV. A construção social da Atenção Primária à Saúde. Brasília: CONASS; 2015.

2. Stein Backes D, Stein Backes M, Erdmann AL, Büscher A, Salazar-Maya AM. Significado da prática social do enfermeiro com e a partir do Sistema Único de Saúde brasileiro. Aquichán [Internet]. $2014 \mathrm{dez}$ [acesso em 2015 jul 7];14(4):560-70. Disponível em: http://www.redalyc.org/articulo.oa?id=74133057010.

3. Brasil. Ministério da Saúde. Secretaria de Gestão do Trabalho e da Educação na Saúde, Departamento de Gestão da Educação em Saúde. Política Nacional de Educação Permanente em Saúde [Internet]. 2009 [acesso em 2014 nov 26]. Disponível em: http://www.saude.es.gov.br/download/PoliticaNacionalEducPermanenteSaude_V9.pdf. (Série B. Textos Básicos de Saúde Série Pactos pela Saúde 2006, v. 9).

4. Miccas FL, Batista SHSS. Educação permanente em saúde: metassíntese. Rev Saúde Pública [Internet]. 2014 set [Acesso em 2014 nov 29];48(1):170-85. Disponível em: http://www.revistas.usp.br/rsp/article/view/80608/84265doi: 8910.2014048004498.

$10.1590 / \mathrm{S} 0034-$

5. Brasil. Ministério da Saúde. Secretaria de Atenção à Saúde, Departamento de Atenção Básica. Política Nacional de Atenção Básica [Internet]. 2012 [acesso em 2014 jun 9]. Disponível em: http://189.28.128.100/dab/docs/publicacoes/geral/pnab.pdf.

6. Minayo MCS. O desafio do conhecimento: pesquisa qualitativa em saúde. São Paulo (SP): Hucitec; 2014.

7. Brasil. Ministério da Saúde. Conselho Nacional de Saúde. Resolução No 466, de 12 de dezembro de 2012. Aprova diretrizes e normas regulamentadoras de pesquisas envolvendo seres humanos [Internet]. 2013 [acesso em 2014 nov 23]. Disponível em: http://sintse.tse.jus.br/documentos/2013/Jun/13/cns-resolucao-no-466-de-12-de-dezembro-de-2012.

8. Viana DM, Araújo RS, Vieira RM, Nogueira CA, Oliveira VC, Rennó HMS. A educação permanente em saúde na perspectiva do enfermeiro na estratégia de saúde da família. Rev Enferm Cent O Min [Internet]. 2015 maio/ago [acesso em 2017 jul 11];5(2):1658-68. Disponível em: http://seer.ufsj.edu.br/index.php/recom/article/view/470/868.

9. Falkenberg MB, Mendes TPL, Moraes EP, Souza EM. Educação em saúde e educação na saúde: conceitos e implicações para a saúde coletiva. Ciênc Saúde Coletiva [Internet]. 2014 mar [acesso em 2014 nov 29];19(3):847-52. Disponível em: http://www.scielo.br/pdf/csc/v19n3/1413-8123-csc-19-03-00847.pdf.

10. Pinto HA, Ferla AA, Matos IB, Zortea AP, Stédile NLR, Barbosa MG. Atenção Básica e Educação Permanente em Saúde: cenário apontado pelo Programa Nacional de Melhoria do Acesso e da Qualidade da Atenção Básica (PMAQ-AB). Divulg Saúde Debate. 2014 out;51:145-60.

11. Santos AR, Coutinho ML. Educação permanente em saúde: construções de enfermeiros da estratégia saúde da família. Rev Baiana Saúde Pública[Internet]. 2014 jul/set [acesso em 2014 dez 9];38(3):708-24. Disponível em: http://rbsp.sesab.ba.gov.br/index.php/rbsp/article/view/695.

12. Barth PO, Aires M, Santos JLG, Ramos FRS. Educação permanente em saúde: concepções e práticas de enfermeiros de unidades básicas de saúde. Rev Eletrônica Enferm 


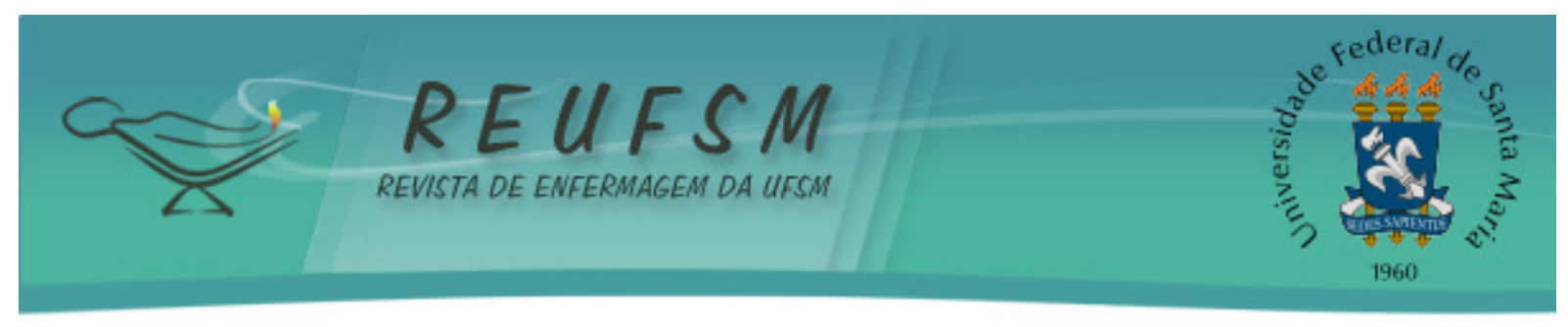

[Internet]. 2014 jul/set [acesso em 2017 jul 11];16(3):604-11. Disponível em: https://www.fen.ufg.br/fen_revista/v16/n3/pdf/v16n3a15.pdf.

13. Weykamp JM, Cecagno D, Vieira FP, Siqueira HCH. Educação permanente em saúde na atenção básica: percepção dos profissionais de enfermagem. Rev Enferm UFSM [Internet]. 2016 abr/jun [acesso em 2016 nov 8];6(2):281-9. Disponível em:https://periodicos.ufsm.br/reufsm/article/viewFile/16754/pdf.

14. Sardinha LP. Educação permanente, continuada e em serviço: desvendando seus conceitos. Enferm Glob. 2013;12(1):324-40.

Data de submissão: 03/01/2017

Data de aceite: 22/09/2017

Autor correspondente: Greici Kelli Tolotti

Endereço: Rua Cristalino Machado Soares, $\mathrm{N}^{\circ}$ 86, Apartamento 02, Bairro Camobi, Santa Maria, Rio Grande do Sul, Brasil.

CEP: 97110210

Email: greici.kellitolotti@gmail.com 